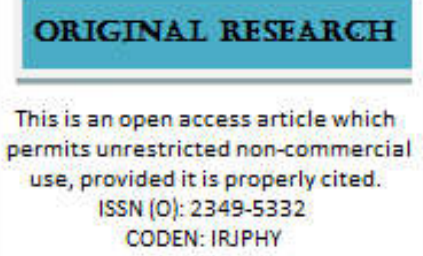

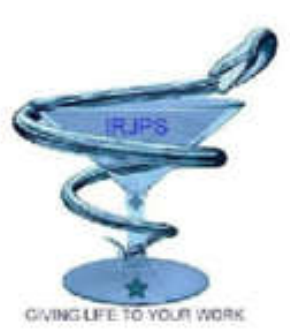

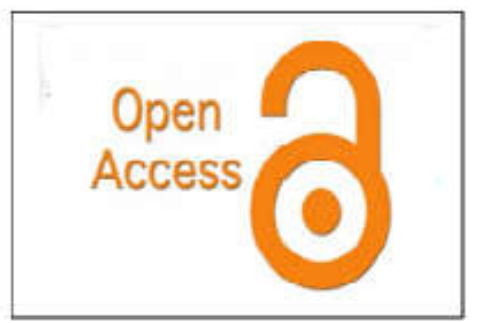

\title{
CASE REPORT ON NON-INDICATED MEDICATIONS
}

\section{Allu Hari Krishna, B. Navya Deepika*, V. Upajna, K. Mahesh Pavan}

Avanthi Institute of Pharmaceutical Sciences, Cherukupally, Vizianagaram

\begin{abstract}
:
A medication error is any preventable event that may cause or lead to inappropriate medication use or patient harm while the medication is in the control of the health care professional, patient, or consumer. This is a case of 19 years old male patient who is suffering from fever with altered sensorium with cerebral malaria and has a history of loose stools. He was prescribed with medications like Inj. Artesunate 120mg IV OD, Tab. Doxycycline 100mg PO BD, Tab. Acetaminophen 500mg PO SOS, Inj. Pantoprazole 40mg IV OD, Inj. Acetaminophen, Syrup. Lactulose $15 \mathrm{ml} \mathrm{H} / \mathrm{S}$, IV fluids. This is an example of medication error where Lactulose is prescribed in case of history of loose stools which may lead to serious electrolyte disturbances in the patient and may cause ADE's.
\end{abstract}

KEY WORDS: Medication error, Lactulose, inappropriate drug.

Corresponding Author: B. Navya Deepika

E-mail: navyaburreddy@gmail.com
Indian Research Journal of Pharmacy and Science; 25(2020)2161-2163; Journal Home Page: https://www.irjps.in DOI: 10.21276/irjps.2020.7.2.8 


\section{INTRODUCTION:}

Prescribing faults and prescription errors are major problems among medication errors. They occur both in general practice and in hospital, and although they are rarely fatal they can affect patients' safety and quality of healthcare. Inadequate knowledge or competence and incomplete information about clinical characteristics and previous treatment of individual patients can result in prescribing faults, including the use of potentially inappropriate medications. ${ }^{1}$

Medication errors can occur at many steps in patient care, from the point of ordering the medication to the time when the patient is administered the drug. Typical errors include the healthcare provider writing the wrong medication, wrong route or dose, or the wrong frequency. These ordering errors account for almost $50 \%$ of medication errors. $^{2}$

\section{Medication errors can occur in:}

- choosing a medicine-irrational, inappropriate, and ineffective prescribing, underprescribing and overprescribing;

- writing the prescription-prescription errors, including illegibility;
- manufacturing the formulation to be used - wrong strength, contaminants or adulterants, wrong or misleading packaging;

- dispensing the formulation-wrong drug, wrong formulation, wrong label;

- administering or taking the drug-wrong dose, wrong route, wrong frequency, wrong duration;

- monitoring therapy - failing to alter therapy when required, erroneous alteration. ${ }^{3}$

\section{CASE REPORT:}

A male patient of age 19years was admitted in General Medicine ward in King George Hospital, Visakhapatnam with a chief complaint of feversince 3 days and altered sensorium since 2 days. Patient has a history of cough with expectoration, vomiting, loose stools and burning micturition. The patient was diagnosed as fever with altered sensorium with cerebral malaria, for which he took Inj. Artesunate 120mg IV OD, Tab. Doxycycline 100mg PO BD, Tab. Acetaminophen 500mg PO SOS, Inj. Pantoprazole 40mg IV OD, Inj. Acetaminophen (if the temperature is above $105^{\circ} \mathrm{F}$ ), Syp. Lactulose $15 \mathrm{ml}$ H/S, IV Fluids.

Table1: Drug utilization pattern

\begin{tabular}{|l|l|l|l|l|l|l|l|l|l|}
\hline DRUG & DOSE & ROA & FREQ & D1 & D2 & D3 & D4 & D5 & D6 \\
\hline Inj. Artesunate & $120 \mathrm{mg}$ & IV & OD & $*$ & $*$ & $*$ & $*$ & $*$ & $*$ \\
\hline Tab. Doxycycline & $100 \mathrm{mg}$ & PO & BD & $*$ & $*$ & $*$ & $*$ & $*$ & $*$ \\
\hline $\begin{array}{l}\text { Tab. } \\
\text { Acetaminophen }\end{array}$ & $500 \mathrm{mg}$ & PO & SOS & $*$ & $*$ & $*$ & - & - & - \\
\hline $\begin{array}{l}\text { Inj. Pantoprazole } \\
\text { Inj. }\end{array}$ & $40 \mathrm{mg}$ & IV & OD & $*$ & $*$ & $*$ & $*$ & $*$ & $*$ \\
\hline $\begin{array}{l}\text { Syp. Lactulose } \\
\text { Symophen }\end{array}$ & $15 \mathrm{ml}$ & PO & IV/S & $*$ & $*$ & $*$ & $*$ & - & - \\
\hline
\end{tabular}

On laboratory examination he had Haemoglobin: 8.0g\%,Platelets: 3.00 lakhs/cumm, WBC: 6400 cells/cumm, Neutrophils: 69\%, Lymphocytes: 28\%, Eosinophils: 2\%, Monocytes: 1\%, Urea: $97 \mathrm{mg} / \mathrm{dl}$, Serum creatinine: $0.9 \mathrm{mg} / \mathrm{dl}$, Bilirubin: $2.2 \mathrm{mg} / \mathrm{dl}$, Alkaline phosphatase: $217 \mathrm{U} / 1$, SGOT: 123.4U/1, SGPT: 30.5U/1, HDL: 8mg/dl, LDL:
$30.8 \mathrm{md} / \mathrm{dl}$, VLDL: $30.2 \mathrm{mg} / \mathrm{dl}$, Triglycerides: $151 \mathrm{mg} / \mathrm{dl}$, Total Cholesterol: $64 \mathrm{mg} / \mathrm{dl}$.

\section{DISCUSSION:}

A medication error is any preventable event that may cause or lead to inappropriate medication use or patient harm while the medication is in the 
control of the health care professional, patient, or consumer and they should be avoided. In this case, the patient received Syrup. Lactulose even though has a history of loose stools. Using Lactulose in case of loose stools is not indicated as it increases the episodes of stools which may lead to dehydration in the patient. This is clear example of unintentional medication error which accounts more than $50 \%$ of medication errors and is similar to the study conducted by Femi Oyebode ${ }^{\mathbf{5}}$, who concluded that prescription errors associated with drug errors and ADEs were frequent in practically all health-care settings.

\section{CLINICAL PHARMACIST INTERVENTION:}

Lactulose, also known as 1,4 beta galactosidefructose, is a non-absorbable synthetic disaccharide made up of galactose and fructose. Its chief mechanism of action is by decreasing the intestinal production and absorption of ammonia. ${ }^{4}$ It increases the episodes of diarrhoea which may lead to dehydration of the patient and therefore proper evaluation of prescription is important and Lactulose usage should be avoided in this case.

\section{CONCLUSION:}

Medication error is sometimes a serious problem as in this case, prescribing lactulose during the condition of loose stools may lead to adverse drug events (ADE) such as dehydration through its osmotic action as Lactulose, which is a laxative has a propensity to bring about large changes in the body's fluid and electrolyte status. The effects are particularly profound regarding the sodium level, which commonly manifests as hypernatremia. This may lead to usage of additional drugs in order to bring the electrolyte imbalance to the normal state which might increase the cost of treatment to the patient. Therefore physician should carefully prescribe drugs and the clinical pharmacist also must evaluate the prescription to identify and rectify such errors.

\section{REFERENCES:}

1. Giampaolo $\mathrm{P}$ Velo and Pietro Minuz; Medication errors: prescribing faults and prescription errors; British Journal of Clinical Pharmacology; 2009 Jun; 67(6): 624-628.

2. Rayhan Tariq; medication errors; https://www.statpearls.com/kb/viewarticle/ 24883.

3. J.K. Aronson; Medication errors: what they are, how they happen, and how to avoid them; An International Journal of Medicine, Volume 102, Issue 8, August 2009, Pages 513-521.

4. Samiran Mukherjee; Savio John; Lactulose; Treasure Island (FL): Stat Pearls Publishing; 2020 Jan.

5. Femi Oyebode; Clinical Errors and Medical Negligence; Medical Principles and Practice; Karger; Med Princ Pract2013; 22: 323-333. 